may ultimately be possible to forecast British meteorological weather by means of magnetic weather some five or six days previous to it.

\section{BAROMETRIC GRADIENT AND WIND}

I HAVE often felt surprised that the superiority in force of northerly and easterly as compared with southerly and westerly winds accompanying any given amount of barometric gradient has, at least until recently, ${ }^{1}$ excited but little attention, seeing that the superiority in question is almost sufficient to suggest itself to any student of daily weather-charts. The comparison of anemometric records for the elucidation of this subject can only be imperfectly made, owing to the fact that there are very few situations at which an instrument can be erected which shall have a really equal exposure to winds from all points of the compass; neither is it possible, as I think, in comparing anemographic records from stations at our different coasts to eliminate the various effects of local inequalities of the earth's surface upon the force of the winds. There are two methods which can be employed in the investigation of this question, which seem to yield reliable, though necessarily somewhat rough and imperfect, results. One of these is to examine separately the anemographs of our imperfectly, but moderately well-exposed, inland stations, in relation to various values of barometric gradient in different directions. The other method is to discuss the means of estimated wind forces in relation to amount and direction of gradient for a large number of years and at a large number of stations. I have hitherto but partially and tentatively employed these two methods, but the results arrived at may posibly be of interest to some readers of NATURE. The mean wind velocities at Stonyhurst Observatory, obtained by me from the hourly readings published by the Meteorological Committee for the years 1874 to 1876 inclusive, for different moderate amounts of atmospheric gradient are as follows :-

\begin{tabular}{c|c|c}
\hline $\begin{array}{c}\text { Gradient per fifteen } \\
\text { nautical miles. }\end{array}$ & $\begin{array}{c}\text { Mean velocity in miles } \\
\text { per hour of winds from } \\
\text { points between S.S. E. } \\
\text { and N.W. (inclusive). }\end{array}$ & $\begin{array}{c}\text { Mean velocity in miles } \\
\text { per hour of winds from } \\
\text { points between N.N.W. } \\
\text { and S. E. (inclusive). }\end{array}$ \\
\hline & 4.31 & 5.53 \\
006 & 5.90 & 6.82 \\
009 & 7.79 & 9.63 \\
012 & 11.09 & 13.97 \\
015 & 13.03 & 15.29
\end{tabular}

The mean wind velocities at Kew Observatory for the same period for similar gradients are as follows :-

\begin{tabular}{|c|c|c|}
\hline $\begin{array}{l}\text { Gradient per fifteen } \\
\text { nautical miles. }\end{array}$ & $\begin{array}{l}\text { Mean velocity in miles } \\
\text { per hour of winds from } \\
\text { points between S.S.E. } \\
\text { and N.W. (inclusive). }\end{array}$ & $\begin{array}{l}\text { Mean velocity in miles } \\
\text { per hour of winds from } \\
\text { points between N.N.W. } \\
\text { and S.E. (inclusive). }\end{array}$ \\
\hline .006 & $4 \cdot 14$ & $6 \cdot 88$ \\
\hline .009 & $6.4 \mathrm{I}$ & 8.63 \\
\hline 012 & $8 \cdot 37$ & 10.93 \\
\hline .015 & II $\cdot 2 \mathrm{I}$ & 14.27 \\
\hline o18 & 13.56 & 16.98 \\
\hline
\end{tabular}

This shows that for any given (moderate) gradient winds from north and east points are stronger than those from south and west points at these stations. The second method, in which the estimated wind-forces have been employed, has been tried by me in the cases of twelve of our English stations for periods varying from ten to three years. The stations examined have been Shields, York, Nottingham, Liverpool, Hurst, Scilly, Dover, London, ${ }^{x}$ Sprung, "Stulien über den Wind und seine Beziehungen zum Luftdruck," ii. p. 6.
Oxford, Cambridge, Yarmouth, and Jersey. At all these stations, excepting Liverpool and Jersey, with very low gradients (viz. from 001 to 005 inch for fifteen miles), mean estimated wind forces from points between northnorth-west and south-east, inclusive, have been higher than those from points between south-south-east and north-west inclusive. With the higher gradients we necessarily find results opposed to this in the cases of stations having a good exposure on the west or south and a bad exposure on the north or east, just as, on the other hand, we find the result above mentioned unduly heightened at stations which have only a good east or north exposure. If however we take stations whose exposure, though not unexceptionable, seems tolerably fair, we find that with somewhat steep as well as with low gradients, north and east winds accompanying any given amount of gradient have a higher estimation than south and west winds accompanying the same. The following table shows results at which I have arrived from an examination of the reports from three stations, viz. the two inland stations of Nottingham and London and the one sea station of St. Mary's, Scilly, which last, while very well exposed to all winds, is perhaps most perfectly so to those from the Atlantic.

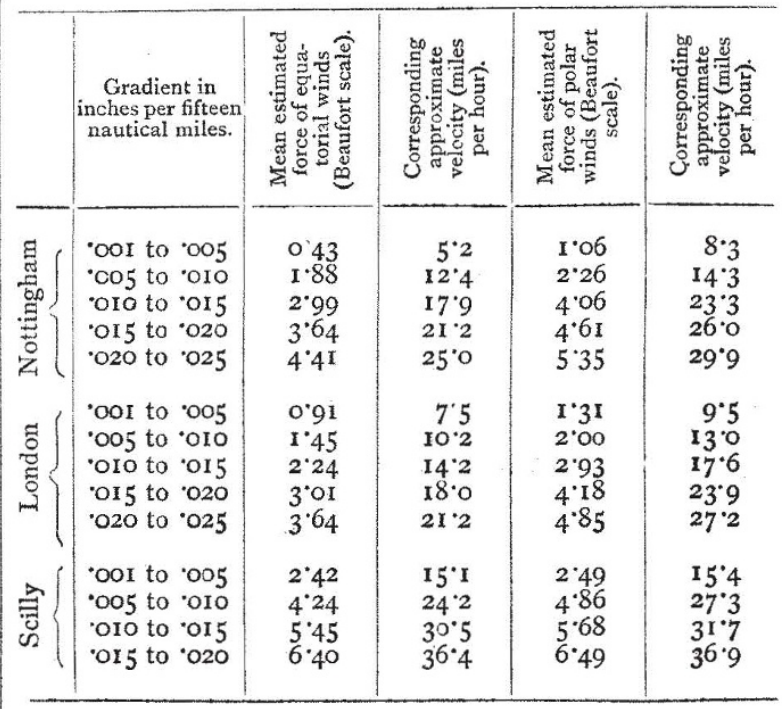

The suggestion which $I$ offer in explanation of this difference of force in the two classes of winds is made with some diffidence, since it involves a hydrodynamical question, the solution of which is somewhat difficult. Since the atmosphere is of greatest density near the poles, while barometric pressure is less near the poles than over the tropics, the pole-ward, and, under the effects of the earth's rotation, eastward movements of the atmosphere, at any given considerable altitude above the earth's surface, must necessarily greatly exceed the corresponding movements at the surface of the earth. "The planes of equal pressure receive," in short, "an ellipsoidal form, the major axis of which is perpendicular to the axis of the earth." 1 Thus the polar areas of low pressure must be far more permanent and far better marked in the upper than in the lower regions of the atmosphere; consequently gradients for westerly winds when occurring at the earth's surface must commonly extend into the higher regions of the atmosphere; while gradients for easterly winds must, on the contrary, be usually accompanied by gradients for westerly winds at no great distance above them. Observations of the movements of the upper cloud, and also of the winds experienced at the summits

" Hann, "Zeitschrift der österreich. Ges. für Meteorologie," vol. xiv. p. 35 . 
of high mountains, fully establish this fact. Observations of the upper clouds further indicate that when a cyclonic disturbance travels eastward in our latitudes, the passage of its centre is usually accompanied (or, more strictly, followed) only by a temporary backing and subsequent veering of the westerly upper-currents, showing that where we have circular isobars at the earth's surface, we should find in the region of the cirrus merely a loop or bend in the isobars for that altitude, could such isobars be drawn. Could we in short have a weather-chart confined to the region of cirrus, we should see in it, in lieu of a deep cyclone, a shallow "secondary" travelling round a portion of the great polar area of depression.

It is true that north-easterly winds may thus be subject to more retardation due to friction at their upper surface than south-westerly winds. But in a fluid like the atmosphere the whole effect of this retardation must be conceived as almost insignificant.

The question, then, that I would ask is this:-May not the fact that any given gradient for an east wind is wholly contributed by the strata of atmosphere near the earth's surface, while a similar gradient for a west wind is contributed by the whole mass of atmosphere overhead, be imagined, consistently with what we know of the mechanics of the atmospheric currents, to give a greater force of wind in the former than in the latter case, at the surface of the earth?

There is one other point to which I may be here permitted to call attention, though it relates to language alone. I have employed above, consistently with common usage, the expression "gradient for" a particular wind ; but this expression appears liable to the objection that it involves a hypothesis, and one which is moreover not in accordance with fact. "A gradient for a southwest wind" signifies a distribution of pressure in which isobars lie south-west and north-east, and in which the lowest pressure is in the north-west and the highest in the south-east. But it is only in the higher latitudes, and on a level surface such as the sea, that this distribution is actually accompanied by a south-west wind. In inland localities, even as far north as the latitudes of the British Isles, it is accompanied by a wind between south-south-west and south; in lower latitudes by a wind still more from the higher to the lower pressures, and finally at the equator such a distribution of pressure would be accompanied by a south-east wind. Further, the expression leads to the needless ignoring of the more local deflections of the winds produced by irregularities of the earth's surface. Would not the expression "north-westward" gradient, simply indicating that barometric pressure decreases most in a north-westward direction, be more correct and equally intelligible? Such a gradient would be one for winds between south-west and south in our northern latitudes, for winds between north-east and east in corresponding southern latitudes, and for winds from the intermediate points over intermediate portions of the globe. "North-westward," "northward," and "north-eastward," \&c., gradients, are moreover slightly shorter expressions than gradients "for south-west," "for west," "for north-west winds," \&c.

W. Clement Ley

\section{SCIENCE IN CHINA}

I.

THE Department for the Translation of Foreign Books at the Kiangnan Arsenal, Shanghai, which has for its object the translation and publication of books relating to the arts and sciences of the West, was established towards the close of the year 1869 , mainly through the instrumentality of Messrs. Hsii and Hwa, natives of Wuseih, and who at that time were on the staff of officials at the Kiangnan Arsenal. The causes which led to the comBy Mr. John Fryer, Chief Translator to the Chinese Arsenal. mencement of this important undertaking are, however, traceable to a much earlier date. In fact, to find a suitable starting-point for its history, it is necessary to go back to the earlier portion of the lives of these two Chinese gentlemen.

Wuseih is an important city on the borders of the $\mathrm{Ta}$ $\mathrm{Hu}$, or Great Lake, in the province of Kiangnan, and has long been noted for its industrial pursuits, as well as the energy and enterprise of its inhabitants, many of whom have emigrated to Japan at various times. It was in this busy place that a little coterie of intelligent scholars was formed, all deploring the hollow and unsatisfying nature of the ordinary routine of Chinese studies. They determined to push their investigations in a more useful and promising field by endeavouring to become acquainted with the great laws of nature, and to gather as much information as they possibly could respecting the various branches of science and art.

Without organising themselves into a society, these aspirants for intellectual light used to have occasional meetings of an informal kind for mutual improvement, each person explaining any new facts or ideas he had acquired. The works of the early Jesuit fathers on mathematics, astronomy, and kindred subjects were carefully read, as well as original native works. But at last, during a visit to Shanghai, they found a valuable prize in Dr. Hobson's translation of a treatise on Natural Philosophy, published at the Lordon Mission Hospital in Canton in the year I855. This book, though of a very elementary character, was like the dawn of a new era upon their minds, enabling them to leap at one bound across the two centuries that had elapsed since the Jesuit fathers commenced the task of the intellectual enlightenment of China, and bringing them face to face with the results of some of the great modern discoveries. Apparatus was extemporised at their homes to perform the various experiments described in its pages, and every new theory or law was put to the test as far as their limited means would permit. Frequent papers were written and circulated from one to another, while queries were continually started by individuals asking for more information on difficult subjects. A pile of such manuscripts accumulated in the house of Mr. Hsü, who, with his son, formed a sort of centre for this little oasis in the midst of a vast desert of ignorance and superstition. Unfortunately, however, these manuscripts were all destroyed when the Taiping rebels captured the city, and the little company were glad to escape with their lives to the neighbouring hills, among which they found a temporary refuge. Even in these trying circumstances they were able to turn their knowledge to good account in different ways so as to alleviate their own hardships as well as those of their fellow-sufferers.

In the third moon of the first year of Tung-che, or 1862 an Imperial edict called upon the Governor-General of the "Two Kiang" provinces to search throughout his jurisdiction for men of talent and ingenuity, and versed in the arts and sciences, who should assist in improving the condition of the Empire. H. E. Tsêng Kwo-fan accordingly selected six men, whose names were duly forwarded to Peking. Among the number were Messrs. Hsü and Hwa, whose reputation as scientists had by this time extended far beyond their native town. They were afterwards invited to an interview with the Governor-General at Anching, and were at once retained on his staff, with the view of their being able to study and perfect themselves in the more useful branches of the foreign arts, sciences, and manufactures.

At that time the rebels were in possession of Nanking, and the surrounding country was in a most unsettled state, so that little could be done in the direction of improvement or study. Mr. Hwa, however, was engaged with others in collecting and preparing such scientific books as China then possessed. This work was after- 